\title{
Experimental and numerical investigation of densification behaviors during powder compaction
}

\author{
Yu LEI*, Shiwei YAN*, Shangyu HUANG*, Wei LIU*, Shiming SUN*, \\ Mengcheng $\mathrm{ZHOU}^{*}$ and Fei FENG** \\ * School of Materials Science and Engineering, Wuhan University of Technology \\ 122 Luoshi Road, Wuhan 430070, China \\ E-mail: huangshy@whut.edu.cn \\ **State Key Laboratory of Materials Processing and Die \& Mould Technology, Huazhong University of Science and Technology \\ 1037 Luoyu Road, Wuhan 430070, China
}

Received: 20 November 2017; Revised: 8 January 2018; Accepted: 31 January 2018

\begin{abstract}
With the rapid development of manufacturing technology powder compaction has been a highly-developed forming technology for manufacturing net shape or near net shape parts with complex geometries and special mechanical performances. An experimental and numerical investigation was made to study the densification behaviors during powder compaction. A series of compaction tests were carried out. A numerical model using multi-particle finite element model (MPFEM) was presented for densification analysis, particles were discretized with fine elements for precise description of inter-particle interactions, and three initial packing structures (hexagonal, tetragonal, and random) were considered in the numerical model. The simulation results of the multi-particle finite element model with random packing structure were in good agreement with experimental results, and can give further insight into the particle-level densification mechanism behind the macroscopic phenomenon in physical compaction tests. Particles' flow behavior, stress field and energy conversion, that are related to the particle rearrangement, contact interactions and local plastic deformation, were detailed analyzed with the numerical model. The effects of friction, particle size and compacting velocity on compaction densification were discussed, and response surface studies of inter-particle friction, particle size and compacting velocity were completed for compaction process optimization.
\end{abstract}

Keywords : Compacting velocity, Energy conversion, Friction, Particle size, Powder

\section{Introduction}

Powder compaction is a highly-developed forming technology for manufacturing net shape or near net shape parts with complex geometries and special mechanical performances (Smith et al., 1998, Zhang et al., 2015). The density distribution of green compacted parts, which is strongly related to the densification behaviors during powder compaction, is vital to the following sintering process and mechanical properties of sintered parts. Any optimization of powder compaction process requires a deep understanding of the relations between influential factors and densification behaviors during powder compaction. The influential factors in industrial compaction application are particle size and its distribution, lubrication, mechanical properties of powder material, and other process parameters including compacting velocity, dimensions of powder volume in the die and die conditions.

Numerical simulation has been widely used in densification analysis of powder compaction, and can contribute to a further understanding of densification mechanism. At present, three numerical approaches are available for densification analysis of powder compaction, which are continuum finite element analysis, discrete element analysis and multi-particle finite element analysis. The continuum finite element analysis considers the compacted part as a continuous media with a certain percent of gas porosity, it can describe the macroscopic densification behaviors, but lack of detailed microscopic information, such as the particle deformation, displacement path and inter-particle 
frictional interactions (Lewis and Khoei, 1998, Gao et al., 1999, Han et al., 2015). The discrete element analysis treats each powder particle as a rigid body without any plastic deformation. The microscopic behaviors during compaction, such as particle rolling, sliding, and flow tendency, can be captured. But the accurate analysis is limited to lower relative density than 0.85 (Huang et al., 2011, Harthong et al., 2012, Olsson et al., 2013). The multi-particle finite element analysis makes full finite element discretization of each powder particle, and has no modeling simplification about contact interactions (Zhang et al., 1998, Ransing et al., 2000, Procopio and Zavaliangos, 2005), then more information about particles' deformation and inter-particle interactions can be available. Some densification studies of powder compaction using multi-particle finite element method have been made, and great deals of progresses in densification analysis have been achieved in recent years. Xin et al. (2002) and Zhang et al. (2009) analyzed the effects of frictional coefficient, Poisson's ratio and material hardening on compaction densification. Zavaliangos (2002, 2003) conducted a two dimensional simulation of 400 particles, and revealed that inter-particle frictions played an important role in macroscopic response, also the significant tensile stresses were developed in particle bodies due to the higher inter-particle friction. Lee et al. (2009) concluded in the multi-particle finite element study that higher compacting velocity resulted in less particle rearrangements and more material hardenings, and small particle size added more frictional energy dissipation during powder compaction. All the previous numerical studies gave a further knowledge about particle-scale densification behaviors during powder compaction, but the macroscopic response(such as stress field, relative density distribution and compression force) throughout the whole loading history has not been clearly revealed from the perspective of particle-scale behaviors(such as particle sliding, rearrangement, particle flow path, plastic deformation and so on).

In this study, compaction tests of Fe powders were carried out, and a numerical model using multi-particle finite element method was presented. The numerical model consists of an actual number of particles, and three initial packing structures of particles were considered in the numerical model. Then the microscopic densification behaviors (such as particle rearrangement, contact interactions, local plastic deformation, particles' flow tendency and energy conversion) by the numerical simulation were detailed analyzed for the further understanding of macroscopic response in physical compaction tests. Also the effects of particle size, friction and compacting velocity on compaction densification were discussed. At last, inter-particle frictional coefficient, particle size and compacting velocity were chosen as independent variables, the response surface studies for minimum compression force at relative density of 0.97 were completed for compaction process optimization.

\section{Powder compaction}

The powder compaction test was performed by a computer controlled universal testing machine (RGM-4100 type manufactured by Shenzhen Reger Company) as shown in Fig. 1. The die and punches are made by strength-enhanced tool steel, which young's modulus is $206 \mathrm{GPa}$. And the die and punches were heated treating. The morphology of the gas atomized Fe powders is shown in Fig. 2, the average diameter is $250 \mu \mathrm{m}$ and the size distribution is shown in Fig. 3. The Fe powders of $0.003 \mathrm{~kg}$ were filled into the close cylindrical die with $10 \mathrm{~mm}$ diameter. Powders were pre-pressed and the height of the pre-pressed compacted part was recorded to calculate the initial relative density. Then the top punch moves downwards at constant velocity of $0.07 \mathrm{~mm} / \mathrm{s}$ to give increasing pressure on powders in the die. The displacement of the top punch is recorded to calculate the relative density of compacted part during compaction. Two force sensors were respectively fixed on the top punch and bottom punch so as to plot the force curves and compute the die wall/powder frictional force. The die wall/powder frictional force equals to the difference value between force from top punch and force from bottom punch. 


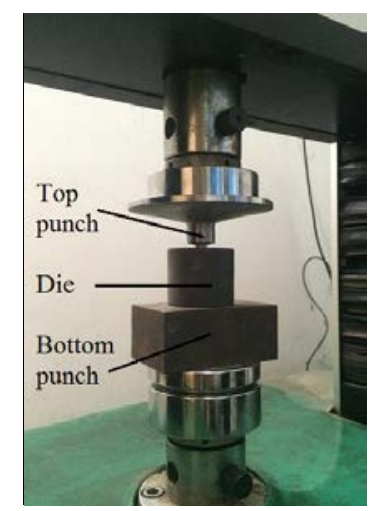

Fig. 1 Configuration of powder compaction test

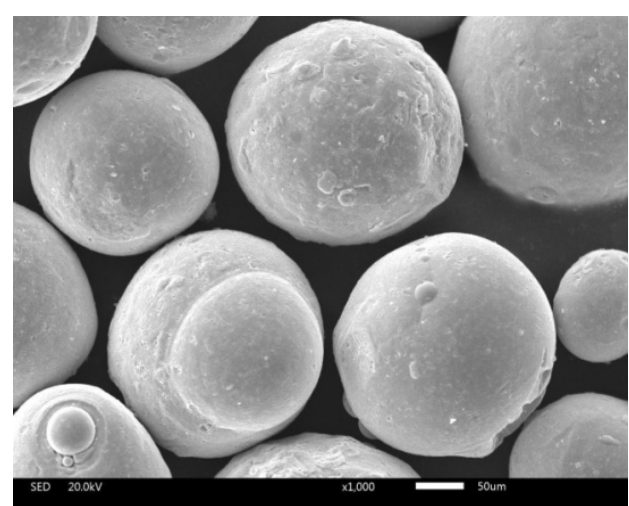

Fig. 2 SEM image of the gas atomized Fe powders

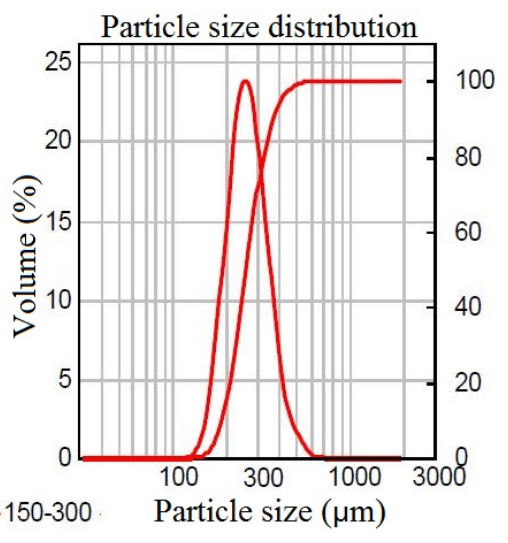

Fig. 3 Size distribution of Fe powders

\section{Multi-particle finite element modeling of Fe powder compaction}

As shown in Fig. 4, each powder particle was discretized in plain stain conditions of 144 quad elements and 169 nodes. A mesh-dependent analysis was made, the outer length of refined mesh on the spherical edge was defined to be $16.35 \mu \mathrm{m}$ and $6.54 \%$ of particle diameter. Three two-dimensional packing structures (tetragonal, hexagonal, and random), that have been employed in microscopic densification simulation (Xin et al., 2002, Procopio and Zavaliangos, 2005, Zhang et al., 2015), were generated for comparison study in order to determine which one is most precise for further studies on compaction densification. About 1200 particles were packed in the die with 5 mm diameter, the enlarged details of three packing structures are shown in Fig. 5. The initial relative density for each packing structure is listed as following: for tetragonal packing is 0.782 , for hexagonal packing is 0.876 , and for random packing is 0.612 .

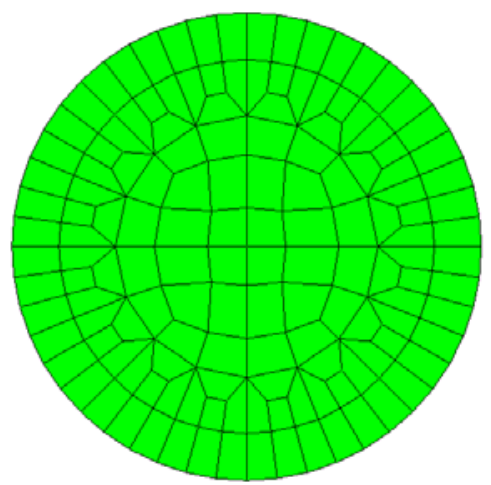

Fig. 4 Discretized element of a powder particle 
(a)

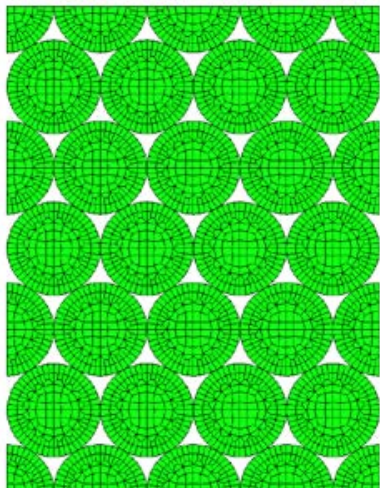

(b)

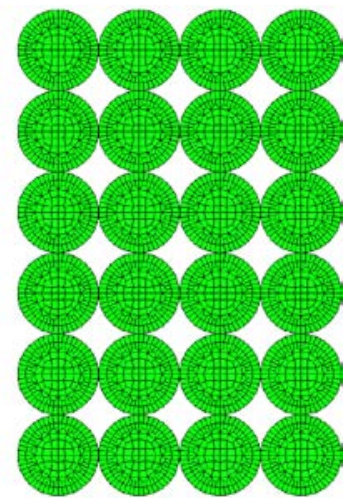

(c)

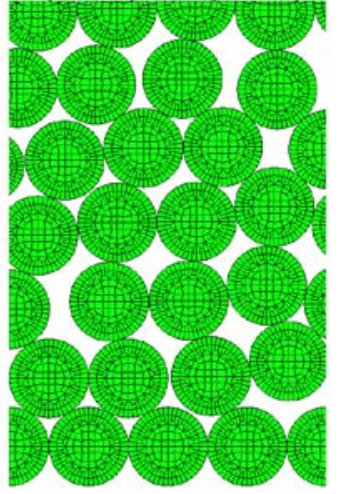

Fig. 5 Enlarged details of packing structures (a: hexagonal, b: tetragonal, c: random)

The Fe powder particles are constitutively assumed as elastic-plastic model. The density is $7850 \mathrm{~kg} / \mathrm{m}^{3}$, the Young's modulus is $200 \mathrm{GPa}$, Poisson's ratio is 0.3 , strength coefficient is $210 \mathrm{MPa}$, and work hardening index is 0.217. The modified coulomb friction model (An et al., 2015) was adopted to describe the frictional interactions among powder particles and the frictional interactions between particles and die walls. Actually, the frictional coefficient is variable and determined by particle characteristics, lubricant content and pressures in contact interface (Cunningham et al., 2004). The Janssen-Walker theory was employed to measure the die wall/powder frictional coefficient with the strain-gauge measurement method (Zhou et al., 2017). The result showed that the die wall/powder frictional coefficient increased with the increasing of relative density, and a small increase occurred when the relative density was over 0.8 . For computing simplification, the die wall/powder frictional coefficient can be defined as a constant, which is 0.17 when the relative density is 0.87 . The inter-particle frictional coefficient is mainly determined by the material, lubrication, and surface roughness, which is difficult to measure in physical test due to its small particle size. A static compaction test was performed with a universal material testing machine, the compacting velocity was $0.01 \mathrm{~mm} / \mathrm{s}$ and the compression force was recorded. Under the defined $0.01 \mathrm{~mm} / \mathrm{s}$ compacting velocity, the finite element model of powder compaction presented in this work was solved by adjusting different inter-particle frictional coefficient. The inter-particle friction coefficient was set as 0.23 in this multi-particle finite element modeling.

The die walls and bottom punch are rigid material and fixed from all directions, the top punch is rigid and moves downwards at an constant velocity of $0.07 \mathrm{~mm} / \mathrm{s}$. LS-DYNA solver was employed in the numerical simulation, mass scaling technique was used to reduce the computing time, and the calculations were performed on Sunway 2000 workstation in China Supercomputing Center (Wuxi City).

\section{Results and Discussion 4.1 Kinetic analysis}

The compression force from top punch is the dominant role in compaction densification. Higher compression force results in higher relative density of compacted parts. The relation between compression force and relative density of compacted part is shown in Fig. 6, the curves from both compaction test and simulations share similar increasing trends. The compression force increases approximately linearly with a small slop when the relative density is under 0.8 , but followed by a drastic increase as soon as the relative density is over 0.8 . 


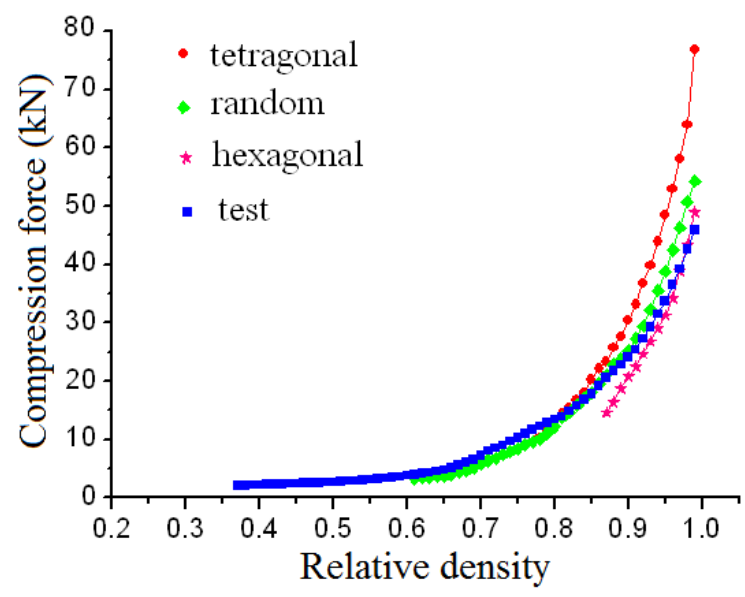

Fig. 6 Compression force -relative density curves of numerical simulations and compaction test

The hexagonal packing structure has a little lower compaction force than compaction test, but illustrates highest accuracy when the relative density is over 0.9, the deformed particles shown in Fig. 7(a) are hexagonal and the adjacent pores are small. The tetragonal packing structure is stiffer than compaction test, which can be explained by the less inter-particle contact surfaces and larger pore volume in tetragonal packing structure. As shown in Fig. 7(b), particles in tetragonal packing structure changed into a similar rectangular shape, particles are more difficult to produce adequate plastic deformation to fill the adjacent pores. The compression force of the random packing structure is a little lower than that of compaction test when the relative density is lower than 0.83 , but becomes a little higher than compaction test when the relative density is higher than 0.83 . As shown in Fig. 7(c), a small number of irregular pores among particles still remain in the compacted part and are hard to be filled by adjacent plastic deformation. Due to the inter-particle friction and inter-locking among irregular deformed particles, the compression force from top punch cannot be effectively transmitted in the highly-densed parts. And the significant tensile stress inside particle bodies usually bring about the potential cracks or fragmentations, which are beneficial to local densification, especially in the high-stress domains. So the random packing structure without any inside cracks or fragmentations illustrates a little stiffer than compaction test when the relative density is higher than 0.83 .

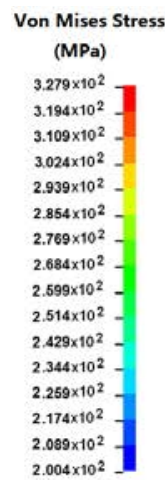

(a)

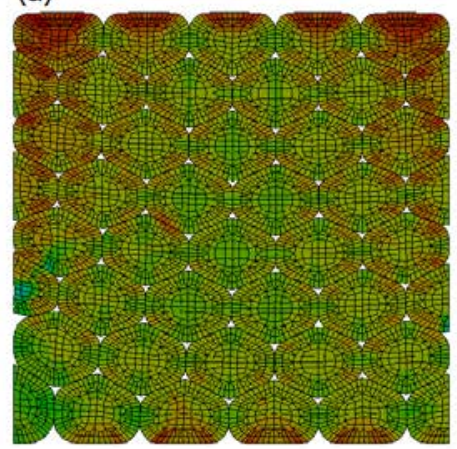

(b)

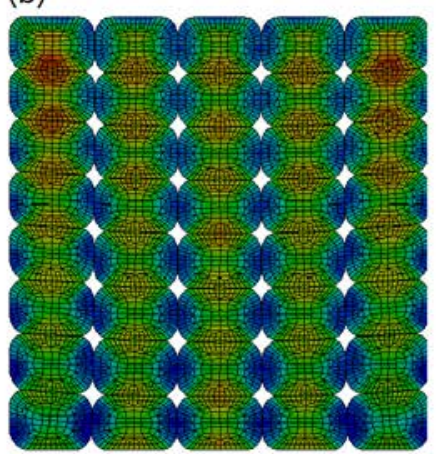

(c)

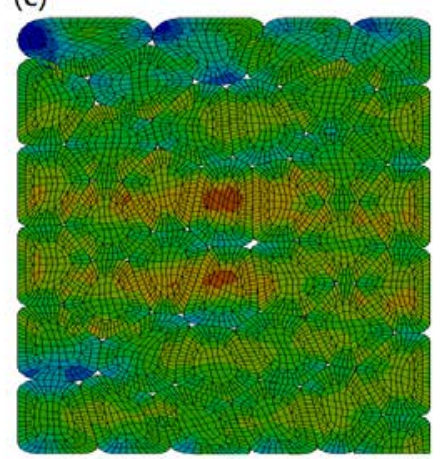

Fig. 7 Deformed mesh of three packing structures under compression force of $40 \mathrm{kN}$ (a: hexagonal, b: tetragonal, c: random)

Deformed particles and isolated pores coexist in the compacted part, the higher relative density of a compacted part means less isolated pores and more plastic deformations of particles. As shown in Fig. 8, the spherical Fe particles have made prominent plastic deformations and changed into various shapes. The complex inter-particle interactions resulted in significant frictional slidings and rearrangements, most of the pores among particles are filled by adjacent plastic deformations and some are isolated by the surface contact instead of the initial inter-particle point contact. 


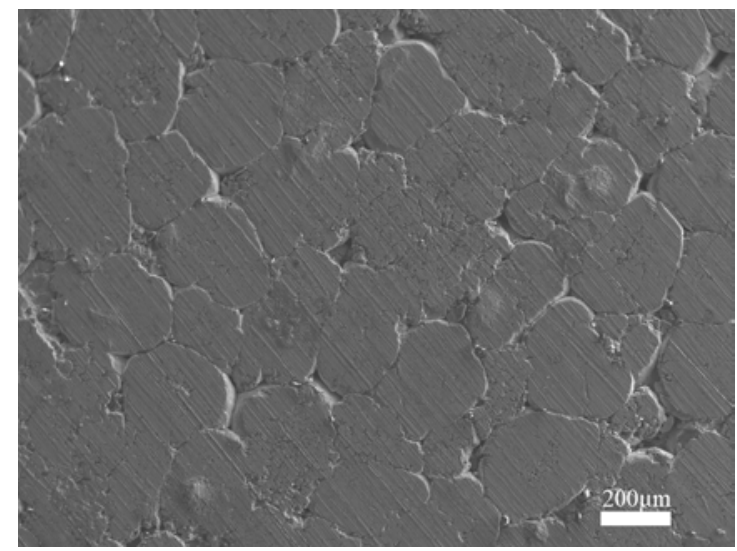

Fig. 8 SEM image of deformed particles with size of $250 \mu \mathrm{m}$

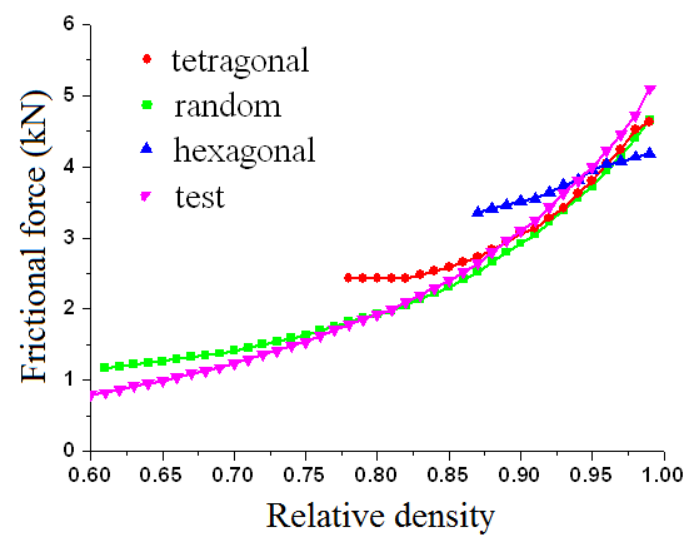

Fig. 9 Die wall/powder frictional force-relative density curves of numerical simulations and compaction test

Friction exists in all contact interactions and is usually regarded as a negative role in powder compaction, it can cause energy loss, density gradients within compacted parts. The presence of die wall/powder friction is a critical consideration throughout the powder compaction process. As shown in Fig. 9, the die wall/powder frictional force shows a gradually increase with the relative density. The die wall/powder frictional force of random packing structure approximately coincides with compaction test, but it is a little lower than compaction test when the relative density of compacted part is higher than 0.82 . This perhaps caused by the constant frictional coefficient in simulation model, which is actually slightly increasing with the increase of relative density (Michrafy et al., 2003, Cunningham et al., 2004). The maximum frictional force at relative density of 0.97 is $4.7 \mathrm{kN}$, which is about $9.4 \%$ of maximum compression force. So the better die wall condition or reasonable lubrication is necessary in powder compaction process.

\subsection{Kinetic analysis}

Due to the higher accuracy in the kinetic analysis in section 4.1, the random packing structure was hereby selected in the densification behavior analysis. As shown in Fig. 10, the Von Mises stress in compacted part with relative density of 0.97 is nouniform and varies from $220 \mathrm{MPa}$ to $580 \mathrm{MPa}$. The highest Von Mises stress domain locates in the top corner near the contact area with top punch. And the Von Mises is mostly above $508 \mathrm{MPa}$, which indicates significant plastic deformations and drastic contact interactions. It can be foreseeable that the stress concentration and stress gradient in the top corner are closely associated with residual stress or potential crack during ejecting operation. The lowest Von Mises stress domain locates in the bottom corner near the contact area with bottom punch, some particles in this domain may go through less plastic deformations and less inter-particle interactions than those in highest Von Mises domain in top corner, also some small pores can be found in this domain. An approximately linear stress decrease along the direction from top punch to bottom punch exists in the center part of the compacted parts. The Von Mises stress distribution of this multi-particle finite simulation is in good agreement with others continuum simulations and experimental results (Diarra et al., 2012, Sethi et al., 2013, Han et al., 2015). The characteristic stress distribution of compacted part is a macroscopic representation of massive frictional interactions and plastic deformations of powder particles, the densification analysis using multi-particle finite element method brings about more convenience to investigate the plastic deformation behaviors of an individual particle in the overall macroscopic stress field. 


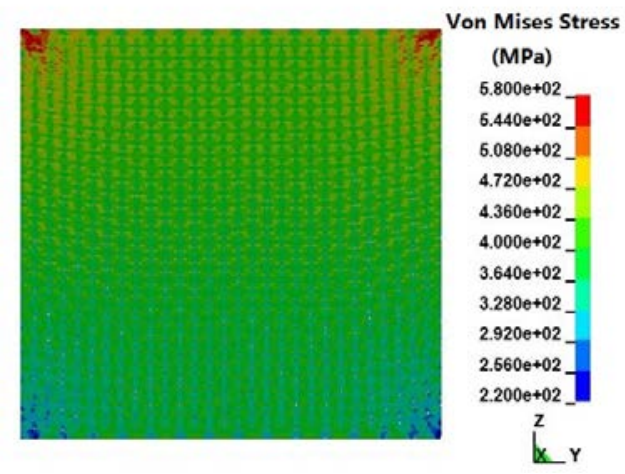

Fig. 10 Equivalent Von Mises stress of compacted part with relative density of 0.97

Under the compression force, particles in the die make various movements that can be described in both axial displacement and radial displacement. As shown in Fig. 11(a), the axial displacement has its maximum at the contact surface with top punch, and represents approximately linear decreases along the direction from top punch to bottom punch. Powders at the same height does not make same axial displacement, the axial displacement in the central part of the compact part is larger than that near the die walls. Due to the frictional constraints from fixed die wall, powders that are close to the die walls lag behind the powders in the center part, the closer to the die wall, the less axial displacement occurs. As shown in Fig. 11(b), particles in the die represent an interesting radial movement. Particles in the top high stress domain flow to the center of the compacted part, while particles in the bottom lower stress domain flow to the die wall, the overall flow path is just like a capitalized X. Pressure gradient is the driving force for particle flow during powder compaction, the stress in top corner of the compacted part is consistently the highest, and the stress in bottom corner of the compacted part is consistently the lowest. So the particle flow that is from top corner to bottom corner via the center of the compacted part can supplement mass flow to the part of low density, the axial displacement is beneficial to homogenous density distribution.

(a)

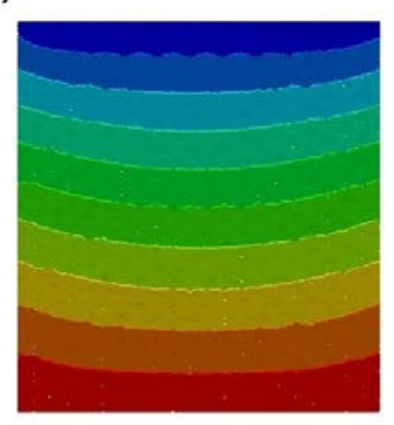

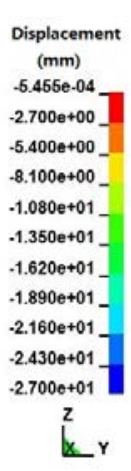

(b)

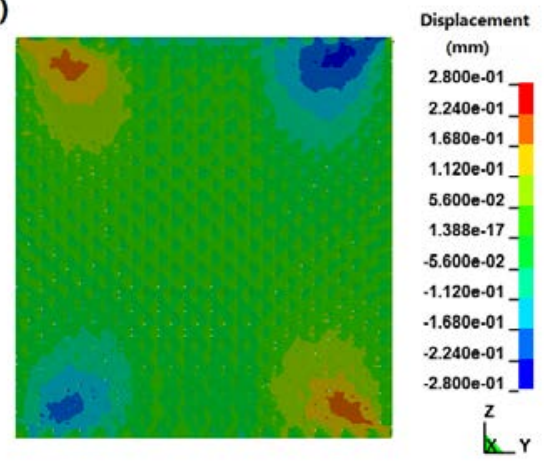

Fig. 11 Displacement contour of compacted part with relative density of 0.97 (a is axial displacement, b is radial displacement)

From the viewpoint of powder compaction system, the external work supplied by compression force is mostly consumed by plastic deformation of particles and frictional interactions. The elastic deformation energy, which is a small fraction of the total energy and temporarily stored in the tools as well as powder particles, will subsequently recover during unloading or ejecting operation. The temperature rise of compacted parts is the result of irreversible energy conversion from plastic deformation work and frictional work.

The energy conversion mechanism during powder compaction can be described as following,

$$
W=W_{f}+W_{p}=Q+\Delta E
$$

where $W$ is the external work of compression force, $W_{f}$ is the total frictional work at both inter-particle interfaces and die wall/powder interfaces, $W_{p}$ is the plastic deformation work of particles, $Q$ is the heat energy transferred from both frictional work and plastic deformation work, and as 


$$
Q=W_{f}+\eta W_{p}
$$

$\eta$ is Taylor-Quinney coefficient for material plastic deformations, and $\Delta E$ is the internal energy stored in compacted part.

$$
Q=m C_{p} \Delta t
$$

where $m$ is the mass of powders in the die, $C_{p}$ is the specific heat capacity at constant pressure, and $\Delta t$ is the temperature rise.

As shown in Fig. 12, the external work on the powders is approximately a quadratic function of relative density. The plastic deformation work also has a similar trend and is a little lower than external work. The frictional work is comparatively small and shows a nearly linear relationship with relative density, which does not make value increase as drastic as external work or plastic deformation work. When the relative density is 0.75 , the frictional work is $3.108 \mathrm{Nm}$ that is $24.9 \%$ of the external work, but it decreases to $16.4 \%$ of the external work at the relative density of 0.97 . It is because the plastic deformation of particles is the domination of densification mechanism when the relative density is high.

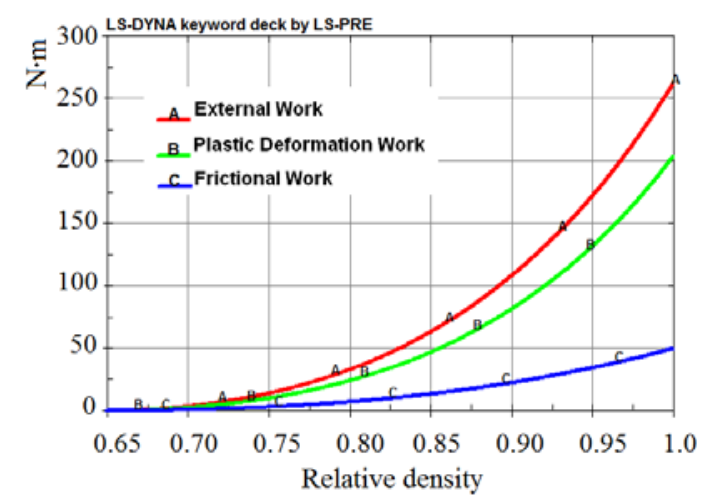

Fig. 12 Energy conversion of powder compaction

\subsection{Effect analysis of friction, particle size and compacting velocity}

Some experimental studies (Sevillano 2001, Eakins and Chapman, 2012, Cai et al., 2015) focused on the macroscopic response to various influential factors during powder compaction, but the particle-scale influential mechanism of the macroscopic response has not been clearly identified. Friction is a major role in powder compaction which causes energy loss and inhomogeneous density distribution. In section 4.2, the die wall/powder friction was revealed to be a major impact on density gradients near the die walls.

In the simulation model for effect analysis of inter-particle friction, the die wall/powder frictional coefficient is fixed and equal to zero. As shown in Fig.13, the compression force increases with the inter-particle frictional coefficient. The compression force under zero inter-particle frictional coefficient is the lowest. In condition of high inter-particle friction, more frictional constraints from adjacent particles can reduce the particle rearrangement, sliding or rotating, the particles have to deform primarily at the contact area, consequently, higher compression force is required to reach the same relative density. As densification progresses, the curves of compression force under different inter-particle frictions approximately converge at the maximum relative density. The above findings indicate that inter-particle friction is a major role in particle rearrangement, sliding or rotating in early stage of compaction while the relative density is low, and the effects of inter-particle friction on compression force begin diminishing in the later stage in which the plastic deformation of particles is dominant. 


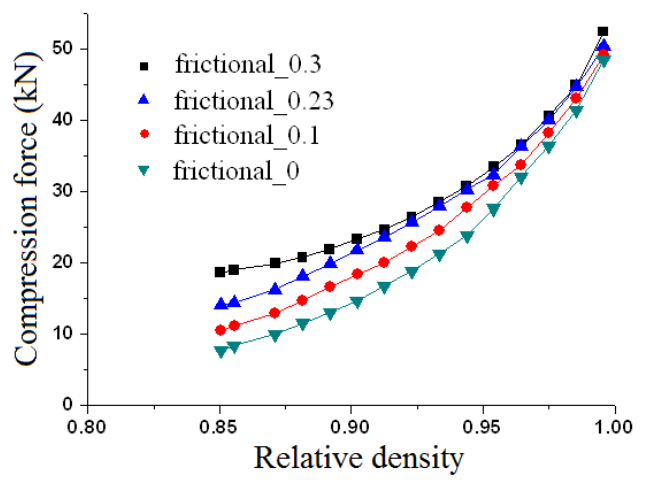

Fig. 13 Compression force-relative density curves when the inter-particle frictional coefficient is $0,0.1,0.23$, and 0.3

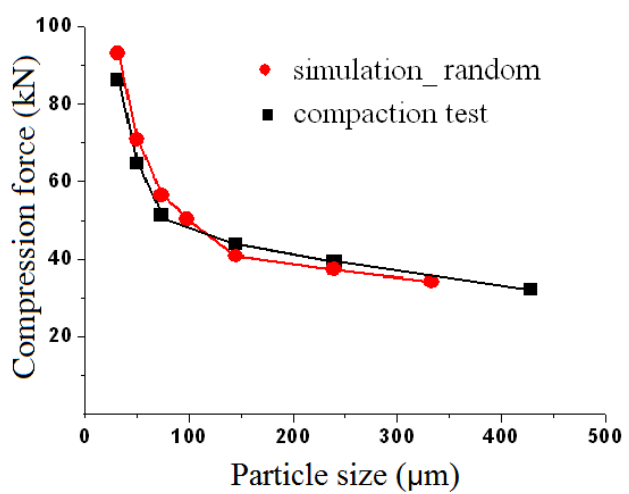

Fig. 14 Compression force-particle size relation when the relative density of compacted part is 0.97

As shown in Fig. 14, the compression force increases with the decrease of particle size. Smaller particle size leads to higher compression force. An approximately linear relation between compression force and particle size can be found when the particle size is over $100 \mu \mathrm{m}$. But a drastic increase occurs to compression force as soon as the particle size in less than $100 \mu \mathrm{m}$, a little size variation can lead to significant fluctuation of compression force.

The observed size effects in compression force can be attributed to several origins, such as plastic strain gradients, more frictional contacts or particle aggregate. By the analysis of energy conversion in powder compaction in Fig. 15, it can be verified that the strength enhancement of plastic resistance as a result of plastic strain gradients (Gao et al., 1999) and its associated local inter-particle contacts are main contributors to size effect in powder compaction. The frictional work is $46.9 \mathrm{Nm}$ that is about $15.6 \%$ of external work when the particle size is $100 \mu \mathrm{m}$, and it increases up to $34 \%$ of the external work when the particle size is $30 \mu \mathrm{m}$. The curve slope of frictional work $(-7.75 \mathrm{Nm} / \mu \mathrm{m})$ is over thirty times than that of plastic deformation work $(-2.45 \mathrm{Nm} / \mu \mathrm{m})$ when particle size is less than $50 \mu \mathrm{m}$, which indicates that frictional interactions and local plastic deformation at inter-particle contact surfaces begin to play more and more important role in densification mechanism for powder of smaller size than $100 \mu \mathrm{m}$.

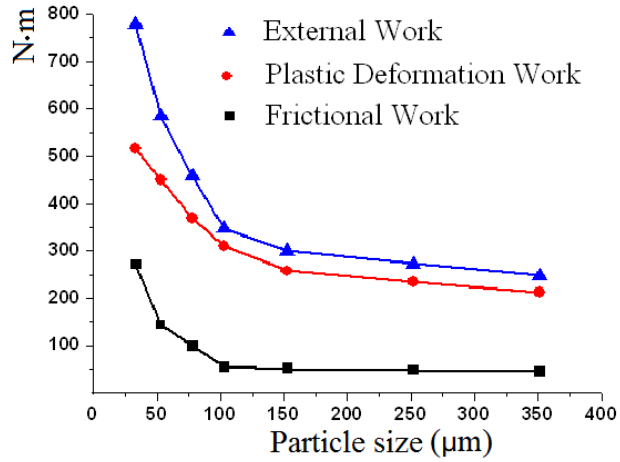

Fig. 15 Energy conversion-particle size relation when the relative density of compacted part is 0.97

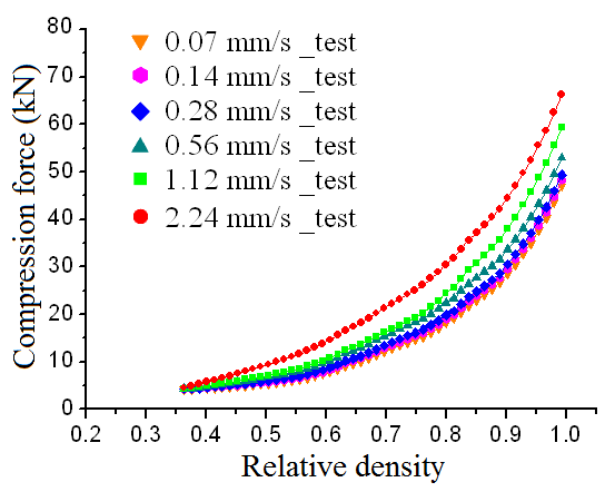

Fig. 16 Compression force-relative density curves when the compacting velocity is $0.07 \mathrm{~mm} / \mathrm{s}$, $0.14 \mathrm{~mm} / \mathrm{s}, 0.28 \mathrm{~mm} / \mathrm{s}, \quad 0.56 \mathrm{~mm} / \mathrm{s}, \quad 1.12$ $\mathrm{mm} / \mathrm{s}, 2.24 \mathrm{~mm} / \mathrm{s}$

Compaction tests at different compacting velocities were carried out and the compression force curves are shown in Fig. 16. It is indicated that the compression force increases with the increase of compacting velocity. Small increase is found when the compacting velocity increases from $0.07 \mathrm{~mm} / \mathrm{s}$ to $0.28 \mathrm{~mm} / \mathrm{s}$, and large increase when the compacting velocity increases from $0.56 \mathrm{~mm} / \mathrm{s}$ to $2.24 \mathrm{~mm} / \mathrm{s}$. It can be explained by the more local densifications as a result of the weak particle flow in shorter time. As shown in Fig. 17(a), greater axial displacement gradient than that in Fig. 11(a) is found in the top region of the compacted part, and small axial displacement gradient in the lower region. Smaller radial displacement as shown in Fig. 17(b) illustrates the limited particle flow from top corner to the bottom corner via the center of compacted part, the local densification in top corner is strengthened and is not conducive to homogenous 
density distribution.

(a)

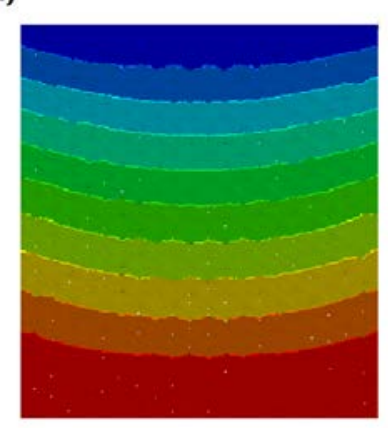

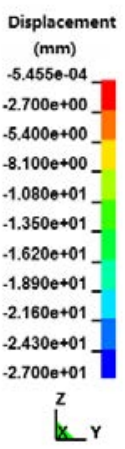

(b)

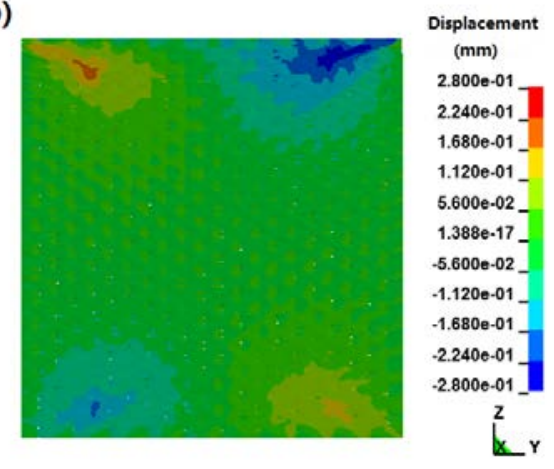

Fig. 17 Displacement contour of compacted part with relative density of 0.97 at $2.24 \mathrm{~mm} / \mathrm{s}$ compacting velocity (a is axial displacement; $\mathrm{b}$ is radial displacement)

It is shown in Fig. 18 that the external work, plastic deformation work and frictional work increase with the increase of compacting velocity. It is because the Fe material is positive strain-rate sensitive, the plastic deformation work becomes larger with the compacting velocity increasing. Also the local densification adds more energy consumptions by local plastic deformations of particles in the top corner. The additional external work for higher compacting velocity is mostly consumed by plastic deformations of powders, the plastic deformation work increases from $83.6 \%$ of external work for $0.07 \mathrm{~mm} / \mathrm{s}$ to $85.2 \%$ for $2.24 \mathrm{~mm} / \mathrm{s}$. The frictional work illustrates an approximately linear relation with compacting velocity.

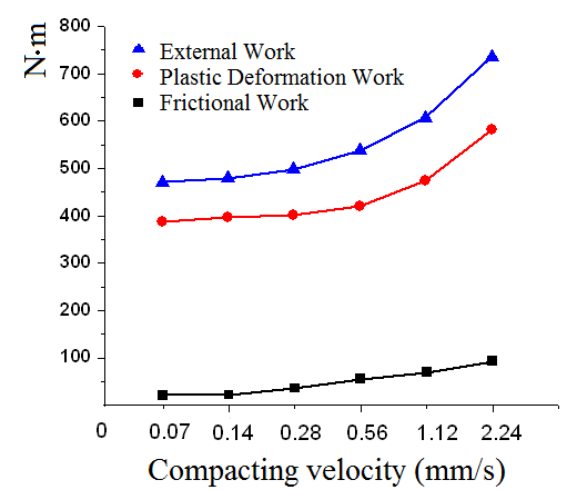

Fig. 18 Energy conversion-compacting velocity relation when the relative density of compacted part is 0.97

\subsection{Response surface studies of inter-particle friction, particle size and compacting velocity}

Response surface methodology is an effective tool for optimization study when two or more independent variables have combined effect on desired response, it can provide sufficient information in a 3D response surface plot and avoid unnecessary experimental tests. In this response surface study, inter-particle frictional coefficient, particle size and compacting velocity are chosen as independent variables, and the minimum compression force at relative density of 0.97 is the desired response. Series of numerical simulations were performed on the independent variables at different levels, then the response surfaces were plotted by cubic polynomial function of maximum compression force.

As shown in Fig. 19, the compression force gradually increases with the inter-particle frictional coefficient and reaches the maximum at the inter-particle frictional coefficient of 0.5 . The compression force is comparatively more sensitive to particle size than inter-particle friction, it makes drastic increase as soon as the particle size is less than 100 $\mu \mathrm{m}$. Particles of $20 \mu \mathrm{m}$ have the biggest compression force in the response surface at inter-particle frictional coefficient of 0.5. An interesting trend can be found for particles of larger than $350 \mu \mathrm{m}$ when the inter-particle frictional coefficient 
is over 0.20 , the compression force is increasing with particle size, this may because particles of large size in the die have to make more plastic deformations to guarantee adequate deformation compatibilities for particle rearrangement, sliding or frictional contact interactions during compaction, so a larger compression force is needed to make necessary plastic deformations in order to eliminate the pores among particles.

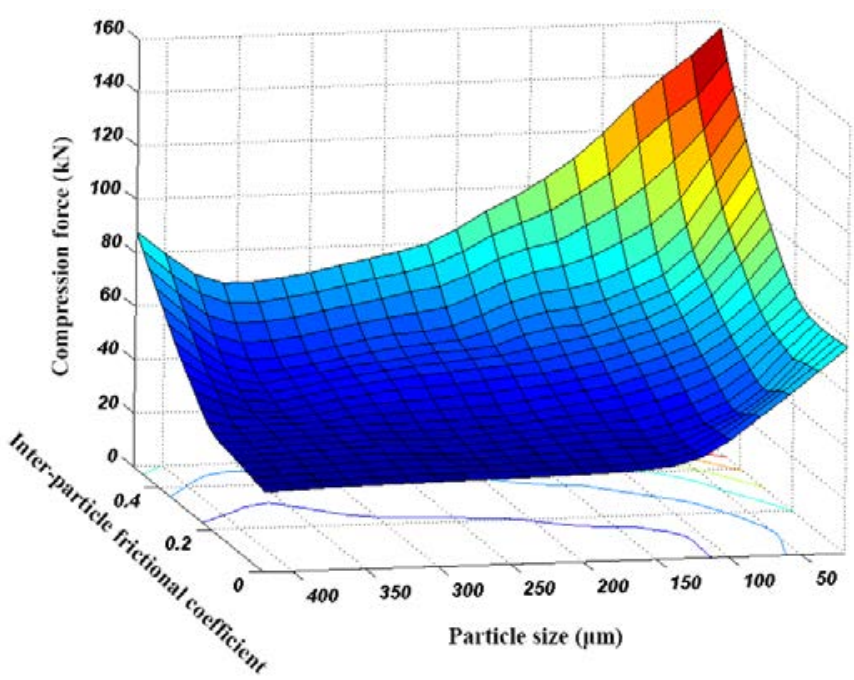

Fig. 19 Response surface of inter-particle frictional coefficient and particle size

As shown in Fig. 20, the compression force is positive sensitive to both inter-particle frictional coefficient and compacting velocity, and reaches the maximum in the response surface at both maximum inter-particle friction and maximum compacting velocity. The compression force is comparatively more sensitive to compacting velocity than inter-particle friction when the inter-particle frictional coefficient is lower than 0.2, but more sensitive to inter-particle friction than compacting velocity when the inter-particle frictional coefficient is larger than 0.2 .

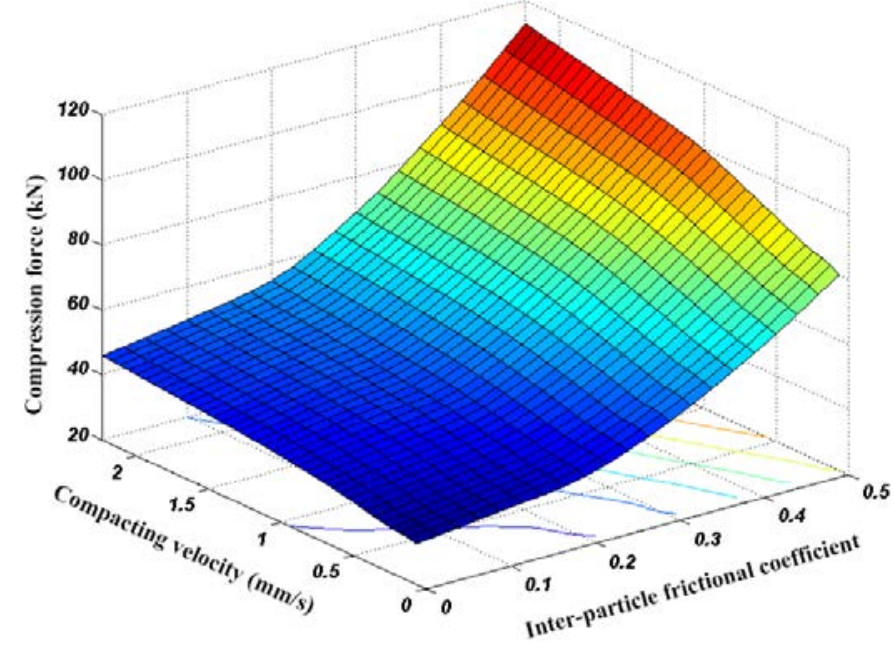

Fig. 20 Response surface of inter-particle frictional coefficient and compacting velocity

As shown in Fig. 21, the response surface illustrates an approximate L shape, the compression force makes a significant increase at different compacting velocities when the particle size is less than $100 \mu \mathrm{m}$. Also the positive sensitivity of compression force to compacting velocity is enhanced when the particle size is decreasing, small increase from $30 \mathrm{kN}$ for $0.07 \mathrm{~mm} / \mathrm{s}$ to $42.72 \mathrm{kN}$ for $2.24 \mathrm{~mm} / \mathrm{s}$ when the particle size is $420 \mu \mathrm{m}$, while larger increase from 77 $\mathrm{kN}$ for $0.07 \mathrm{~mm} / \mathrm{s}$ to $109.6 \mathrm{kN}$ for $2.24 \mathrm{~mm} / \mathrm{s}$ when the particle size is $20 \mu \mathrm{m}$. 


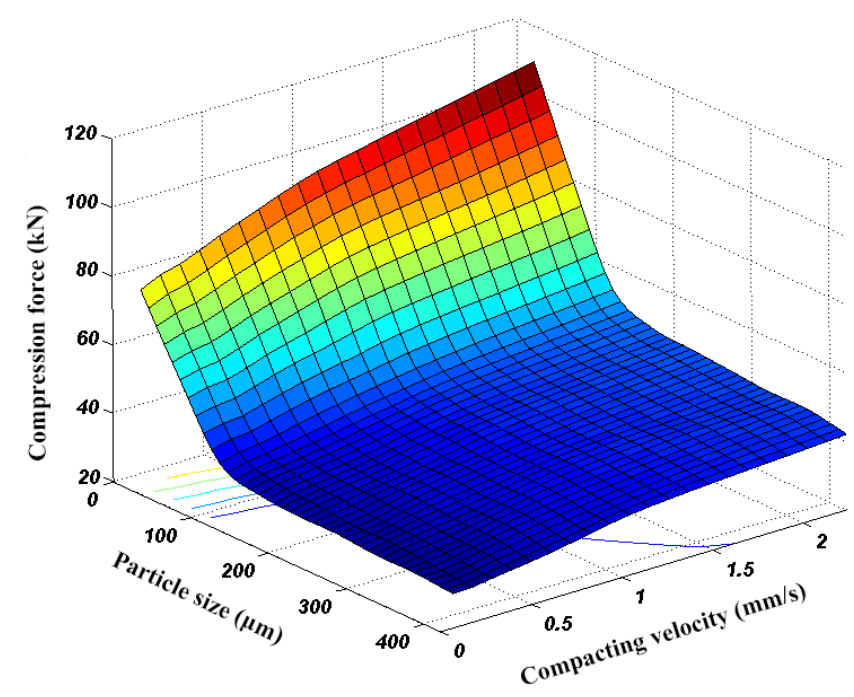

Fig. 21 Response surface of particle size and compacting velocity

\section{Conclusions}

A series of compaction tests of Fe powders were carried out. A numerical model using multi-particle finite element method was presented. The particle-level densification mechanism (such as particle rearrangement, contact interactions, local plastic deformation, particles' flow tendency and energy conversion) behind the macroscopic phenomenon in physical compaction tests was detailed analyzed. The effect analysis of particle size, friction and compacting velocity on compaction densification was completed for compaction process optimization. The conclusions can be drawn from the experimental and simulated results as following:

(1) The numerical results of the multi-particle finite element model with an actual number of particles were in good agreement with experiment results, and can give further insight into the particle-level densification mechanism behind the macroscopic response in physical compaction tests. The macroscopic response (such as stress field, frictional behavior, relative density distribution and compression force) throughout the whole loading history was revealed from the perspective of particle-scale behaviors (such as particle sliding, rearrangement, particle flow path and plastic deformation).

(2) The compression force increases with both the die wall/powder friction and inter-particle friction. Higher inter-particle friction brings about more frictional energy consumptions during early stage of powder compaction, and is a major role in particle rearrangement, sliding or rotating. The die wall/powder friction is the major impact on radial density gradients near the die walls. Smaller particle size leads to higher compression force. As a result of plastic strain gradients and the increasing associated local inter-particle contacts, the strength enhancement of plastic resistance can be used to explain the size effect in powder compaction. The compression force increases with the increase of compacting velocity, which can be explained by the more local densifications as a result of the weak particle flow in shorter time. The additional external work for higher compacting velocity is mostly consumed by plastic deformations of powders.

(3) The compression force is comparatively more sensitive to particle size than inter-particle friction, especially when the particle size is less than $100 \mu \mathrm{m}$. The compression force reaches the maximum at both maximum inter-particle friction and minimum particle size. But when the particle size is larger than $350 \mu \mathrm{m}$ and the inter-particle frictional coefficient is over 0.20 , the compression force is increasing with particle size. The compression force is comparatively more sensitive to compacting velocity than inter-particle friction when the inter-particle frictional coefficient is lower than 0.2, but more sensitive to inter-particle friction than compacting velocity when the inter-particle frictional coefficient is larger than 0.2 . The compression force makes a significant increase at different compacting velocities when the particle size is less than $100 \mu \mathrm{m}$. Also the positive sensitivity of compression force to compacting velocity is enhanced when the particle size is decreasing. 


\section{Acknowledgment}

This work was financially supported by the National Natural Science Foundation of China (No.51475345, No.51705169), the Open Fund Project of State Key Laboratory of Materials Processing and Die \& Mould Technology (P2018-013), and the China Postdoctoral Science Foundation (2017M610472).

\section{References}

An, X., Zhang, Y., Zhang, Y., and Yang, S., Finite element modeling on the compaction of copper powder under different conditions, Metallurgical and Materials Transactions A, Vol.46 (2015), pp.3744-3752.

Cunningham, J. C., Sinka, I. C., and Zavaliangos, A., Analysis of tablet compaction. i. characterization of mechanical behavior of powder and powder/tooling friction, Journal of Pharmaceutical Sciences, Vol.93 (2004), pp.2022-2039.

Cai, Z., Wang, R., Peng, C., and Zhang, C., Effect of particle size on microstructure and cold compaction of gas-atomized hypereutectic al-si alloy powder, Metallurgical and Materials Transactions B, Vol.46 (2015), pp.824-830.

Diarra, H., Mazel, V., Boillon, A., Rehault, L., Busignies, V., and Bureau, S., Finite element method (fem) modeling of the powder compaction of cosmetic products: comparison between simulated and experimental results, Powder Technology, Vol.224 (2012), pp.233-240.

Eakins, D. E., and Chapman, D. J., The influence of particle morphology on the dynamic densification of metal powders, American Institute of Physics, Vol.1426 (2012), pp.1494-1494.

Gao, H., Huang, Y., Nix, W. D., and Hutchinson, J. W., Mechanism-based strain gradient plasticity- i. theory, Journal of the Mechanics and Physics of Solids, Vol.47 (1999), pp.1239-1263.

Huang, H., Tutumluer, E., and Huang, H., Discrete element modeling for fouled railroad ballast, Construction and Building Materials, Vol.25 (2011), pp.3306-3312.

Harthong, B., Jérier, J. F., Richefeu, V., Chareyre, B., Dorémus, P., and Imbault, D., Contact impingement in packings of elastic-plastic spheres, application to powder compaction, International Journal of Mechanical Sciences, Vol.61 (2012), pp.32-43.

Han, P., An, X. Z., Zhang, Y. X., and Zou, Z. S., Fem modeling on the compaction of Fe and Al composite powders, Journal of Mining \& Metallurgy, Vol.51 (2015), pp.163-171.

Lewis, R. W., and Khoei, A. R., Numerical modelling of large deformation in metal powder forming, Computer Methods in Applied Mechanics and Engineering, Vol.159 (1998), pp.291-328.

Lee, K. H., Lee, J. M., and Kim, B. M., Densification simulation of compacted Al powders using multi-particle finite element method, Transactions of Nonferrous Metals Society of China, Vol.19 (2009), pp.68-75.

Michrafy, A., Kadiri, M. S., and Dodds, J. A., Wall friction and its effects on the density distribution in the compaction of pharmaceutical excipients, Chemical Engineering Research and Design, Vol.81 (2003), pp.946-952.

Olsson, E., and Larsson, P. L., A numerical analysis of cold powder compaction based on micromechanical experiments, Powder Technology, Vol.243 (2013), pp.71-78.

Procopio, A. T., and Zavaliangos, A., Simulation of multi-axial compaction of granular media from loose to high relative densities, Journal of the Mechanics and Physics of Solids, Vol.5 (2005), pp.1523-1551.

Ransing, R. S., Gethin, D. T., Khoei, A. R., Mosbah, P., and Lewis, R. W., Powder compaction modelling via the discrete and finite element method, Materials and Design, Vol.21 (2000), pp.263-269.

Smith, L. N., Midha, P. S., and Graham, A. D., Simulation of metal powder compaction, for the development of a knowledge based powder metallurgy process advisor, Journal of Materials Processing Technology, Vol.79 (1998), pp.94-100.

Sevillano, J. G., Size effects in powder compaction, Journal of Materials Research, Vol.16, (2001), pp.1238-1240.

Sethi, G., Hauck, E., and German, R. M., High velocity compaction compared with conventional compaction, Materials Science and Technology, Vol.22 (2013), pp.955-959.

Xin, X. J., Jayaraman, P., Jiang, G., Wagoner, R. H., and Daehn, G. S., Explicit finite element method simulation of consolidation of monolithic and composite powders, Metallurgical and Materials Transactions A, Vol.33 (2002), pp.2649-2658. 
Zavaliangos, A., A multiparticle simulation of powder compaction using finite element discretization of individual particles, MRS Online Proceedings Library Archive, Vol.731 (2002), pp.169-176.

Zavaliangos, A., A numerical study of the development of tensile principal stresses during die compaction, Particulate Science and Technology, Vol.21 (2003), pp.105-115.

Zhang, J., A study of compaction of composite particles by multi-particle finite element method, Composites Science and Technology, Vol.69 (2009), pp.2048-2053.

Zhang, Y. X., An X. Z., and Zhang Y. L., Multi-Particle FEM Modeling on Microscopic Behavior of 2D Particle Compaction, Applied Physics A, Vol.118 (2015), pp.1015-1021.

Zhou, M., Huang, S., Hu, J., Lei, Y., Xiao, Y., Li, B., Yan, S. and Zou, F., A density-dependent modified Drucker-Prager Cap model for die compaction of Ag57.6-Cu22.4-Sn10-In10 mixed metal powders, Powder Technology, Vol.305 (2017), pp. 183-196. 